\title{
The paths from walk preference to walk behavior: Applying latent factors in structural equation modeling
}

\author{
Matthew A. Coogan a \\ New England Transportation \\ Institute
}

\author{
Thomas Adler \\ Resource Systems Group Inc.
}

\author{
Karla H. Karash \\ TranSystems Inc.
}

\begin{abstract}
A structural regression model has been developed to explore the relationship among key factors in the explanation of utilitarian walking. The model examines the relationship between and among unobserved, or "latent," factors that reflect (1) the values and preferences operant at the time of residential selection; (2) the urban form of the neighborhood; (3) the urban form of the residence; (4) the level of auto dependency; and (5) the extent to which the neighborhood is found satisfactory by the participant and those whose opinions he/she respects. The model allows the detailed examination of the paths from initial inclination toward a neighborhood with walkable destinations, through a series of mediating unobserved factors, each of which might either impede or facilitate the adoption of utilitarian walking. Analysis of the model results shows that values and preferences held at the time of residential selection are directly associated with the amount of utilitarian walking undertaken and indirectly associated through their influence on the choice of the built environment and the extent of auto orientation. The model is designed to facilitate the observation of the manner in which the various factors interact.
\end{abstract}

Keywords: Walking, structural equation modeling, residential selection, attitudes, urban form, auto dependency

\section{$1 \quad$ Introduction}

At present a wide variety of research strategies (summarized by Cao et al. 2008) are being applied to the question of how attitudes and beliefs interact with physical characteristics in the analysis of transportation, ranging from linear regression (Kitamura et al.) to the application of attitudes in the creation of market segment clusters to better predict mode share (Outwater et al. 2003; Walker and Li 2007). This paper explores the full application of structural equation modeling (SEM) to the question of the relationship between attitudes/beliefs, land-use characteristics, orientation to automobiles, and the amount of utilitarian walking undertaken. The full application of SEM builds on some earlier application of exploratory factor analysis and examines the interrelationship of latent, unobserved factors, applying a series of steps including confirmatory factor analysis, model specification, identification, model estimation and refinement using specification searches to result in maximized "goodness of fit" for the model.

The question of the integration of data from several disciplines (e.g., geography, civil engineering, and social psychology) and several sources (e.g., census, geographic information systems, attitudinal surveys) in the analysis of behavior has been a challenge for several decades (see Giles Corti and Donovan 2002 for an early example and Van Acker 2010 for a more recent example.) This paper applies several established descriptions of urban form, including "density, diversity and design" (Cervero and Kockelman) to a sample derived from 11 transit-oriented metropolitan areas from all parts of the United States. In theory, the use of structural regression modeling (utilizing unobserved latent factors that underlie the observed manifest variables) has several advantages over the use of SEM path models utilizing only directly observed factors, including the ability to gain full advantage from observed variables having diverse scales and formats. In addition, it allows the explicit incorporation of errors of measurement. Theoretically, the concept of underlying latent unobservable factors revealed through our direct observations seems applicable to the exploration of the question of how key factors interact, whether or not our observed measures completely capture the patterns. The correlation has been documented between the amount of walking and attitudes/values reflecting a positive predisposition thereto (TCRP 2008, Chapter 8). What is less clear-and the subject of continuing analysis in the literature-is the way in which those attitudes and values interact with the realities of the built environment, and how that interaction impacts the amount of utilitarian walking undertaken. This paper seeks to fill that void.

Concern for better integration of factors concerning both residential selection and choice of mode spurred the creation

\footnotetext{
${ }^{a}$ cooganmatt@aol.com
} 
by the Transit Cooperative Research Program (TCRP) of the Transportation Research Board (TRB) of the project Understanding How Individuals Make Travel and Location Decisions: Implications for Public Transportation, published as TCRP Report 123 (2008). This study was tasked with two challenging but separate assignments: to examine the interaction between residential selection and mode choice and to apply methods borrowed from social psychology - specifically the Theory of Planned Behavior (TPB). The study included a thorough application of the TPB to the process of residential choice, which is presented elsewhere and not summarized in this paper (see TCRP 2008.) The survey instrument was designed to illicit responses consistent with the requirements of the TPB.

\section{Literature}

Defining utilitarian walking. Utilitarian walking, also known as walking for transport, has garnered much interest over the last decade (e.g., Newman and Kenworthy 1989; Coogan 2006). The published literature has well established that higher-density urban areas are characterized by higher amounts of walking to shop, to work, to visit, and to find recreation than are lower-density suburban neighborhoods: the same literature has established that a much weaker association exists for walking for pleasure or walking for exercise (Saelens and Handy 2008, p. S562; Coogan et al. 2009). Indeed, a suburban person may walk the dog for a longer distance than the urban person. The present paper focuses only on utilitarian walking.

Longitudinal studies. Most studies we reviewed make some reference to the desirability of a true longitudinal design, preferably with a large sample to address the question of the impact of the change in neighborhood to change in the amount of walking. An epidemiological study (Coogan et al. 2009) of more than 20,000 women in New York, Chicago, and Los Angeles examined the change in walking rates for those who moved neighborhoods between 1995 and 2001. Examining the possible role of housing density, road networks, availability of public transit, sidewalks, and parks, the study concluded that residential density was the strongest explanatory variable for the change in level of walking, followed by transit availability. Those women who moved to a lower-density neighborhood were 36 percent more likely to decrease their walking than those moving to a neighborhood of similar density. Women who moved to a higher-density neighborhood were 23 percent more likely to increase their utilitarian walking than those who moved to a neighborhood of similar density. For the sample as a whole (including those women who did not change neighborhoods), density, again, proved to be the most important urban form variable in the explanation of level of utilitarian walking. When walking rates of those in the highest quintile of residential density were compared with those in the lowest quintile of density, an unadjusted odds ratio of 4.21 was reported. More importantly, an adjusted odds ratio of 2.72 was reported to describe the impact of residential density above and beyond (controlling for) variables including neighborhood socioeconomic status, age, education, sample city, body mass index, smoking, alcohol, marital status, energy intake, hours of $T V$ viewing, and a crime index. Of the elements of urban form studied, density proved to be more important than the routemiles of bus or bus service, which had a similarly adjusted odds ratio of 1.44. Urban form characteristics found to be not significant for utilitarian walking included size of blocks, sidewalk coverage, intersections per square mile, distance to parks, and distance to transit stops. In the examination of walking for exercise, residential density was the only urban form variable to have a significant association with walking for exercise, but it was much weaker than that for walking for transport.

Use of latent factors in SEM. Structural equation modeling (SEM) has been identified as a logical methodology for examining processes in which some form of impact is direct in nature, while other forms of impact are indirect. SEM, characterized by the analysis of relationships among unobserved, or "latent," factors, is the logical form of SEM to apply in such an analysis. Perhaps surprisingly, there are very few examples of the application of full-scale structural regression modeling to walking behavior in the literature, most being reliant on "path diagrams," which rely on factors derived externally and not simultaneously applied within the model (e.g., Bagley and Mokhtarian 2002; Cao et al. 2007). Some articles have directly discussed the decision not to use latent factors (Simma and Axhausen 2003; Naess 2009; Scheiner, Holz-Rau 2007), while others simply refer to "path diagrams" as a form of SEM, without making reference to the lack of use of latent factors.

The self-selection issue in the literature. Much of the literature on the subject of the relationship between attitudes, urban form, and transportation choice (e.g., walking) focuses on the concept of residential self-selection. Under one interpretation of this theory, the values and preferences expressed at the time of residential location might be interpreted as a more powerful explanation of transport behavior than the urban form characteristics of the residential location. Thus, given the observation that residential areas with higher density have more sustainable patterns of transportation, this might be attributed to the attitude set of the residents, not the characteristics of the location. Under such a theory, it would make little sense to build more 
high-density neighborhoods if urban form indeed had no impact on transport behavior (see Guiliano 1995).

This concept was flagged by a highly influential paper by Kitamura et al. (1997), in which the attitudes and preferences of the sample population had higher explanatory power for transport behavior than the characteristics of the residential location. A later paper by Bagley and Mokhtarian came to the conclusion that with respect to direct and total effects, "attitudinal and lifestyle variables had the greatest impact on travel demand among all explanatory variables, while residential location type had little separate influence on travel behavior" (Cao and Mokhtarian 2008). Since the time of those two papers, subsequent research has concluded that the effect of self-selection does not negate an important role for the characteristics of the built environment in the explanation of transportation behavior. Pinjari et al. (2007) concluded that while effects of self-selection do exist, "even after accounting for these effects, it is found that built environment attributes can indeed significantly impact commute mode choice behavior." Cao et al. (2009) reviewed 38 empirical studies and found that "virtually all of the studies reviewed found a statistically signifcant influence of the built environment remaining after selfselection was accounted for...." Bohte summarized that "the studies that did compare the effects, generally found that the effect of the built environment was greater than the effect of self-selection." Bohte included a summary review of 13 major studies and found only two in which attitudes had a stronger role than the built environment - the paper by Kitamura et al. (1997) and that of Bagley and Mokhtarian (2002). Some researchers have addressed the controversy directly, such as Naess (2009), who wrote: "Several researchers within the field of land use and travel have claimed that self-selection of residents into geographical locations matching their travelling preferences precludes researchers from drawing firm conclusions about influences of residential location on travel. This paper counters this position."

\section{Considerations for the development of the model}

Consistent with the conclusion in the reviewed literature that both attitudes and the built environment impact travel behavior, our research plan was designed to test the hypothesis that attitudes affect the choice of location and transportation behavior, and that the built environment has an incremental impact on transportation behavior that is above and beyond that of the attitudes. This paper also focuses on the question of auto dependency as it relates to walking. Auto dependency has been examined as a variable in the study of correlates of transportation behavior, and mode choice in particular. Sev- eral authors (e.g., Lerman 1977) have suggested further work on the possible role of auto ownership and modal behavior. Highly relevant to the present study is a series of studies by Stradling and his colleagues (Stradling 2003, 2004). The concept was further developed by Anable (2005), who explored the logic of auto dependency in a larger context of possible mode change. The role of auto ownership as a possible mediator between urban form and modal choice is discussed by Bhat and Gou (2006), Cao et al. (2007 and 2008a), Scheiner and Holz-Rau (2007), Naess (2009), and Van Acker and Witlox (2010). A paper by the present authors, based on this dataset (Coogan et al. 2007), concluded that auto ownership and auto dependence justified further examination in the study of the relationship between attitudes/values, the built environment, and their interactive impact on utilitarian walking.

In our model, five factors contribute to walking behavior: (1) attitudes/preferences toward a walkable neighborhood, (2) urban form of the community, (3) urban form of the residence, (4) auto dependency, and (5) satisfaction with the neighborhood.

The existence of a dense urban form does not, of course, cause anyone to walk. The path from values to intentions to behavior has been explored in social psychology over the past 40 years. At its most basic, the Theory of Planned Behavior (TPB) can be seen as a model in which one forms an inclination to undertake an action, taking into consideration one's own preference and those of the social world around him/her (see Warner and Aberg, p. 509)—which inclination is either impeded by the level of challenge associated with the difficulty of undertaking the action, or enabled by the conditions supportive of undertaking the action. In the process documented within the TPB, the individual must assess his/her level of behavioral control to overcome whatever obstacles stand between his/her volition and undertaking the behavior (Ajzen 1991).

Logically, the behavior of utilitarian walking is influenced by the initial inclination to walk, which is then mediated by an external environment that either impedes or enables the effectuation of the volition (Naess 2009; Bohte 2010 p. 18). Many advances in the literature describing the propensity to walk have been accomplished by merging quantitative descriptions of the built environment with quantitative descriptions of values and attitudes toward a pro-walking lifestyle (e.g., Giles-Corti and Donovan 2002; Frank et al. 2007; Handy et al. 2005 and 2008). A strong base has been established that links some level of personal values/preferences and some level of urban form to the explanation of the amount of walking (see TCRP 2008, ch. 8). What is less clear is just how, and even when, that set of values and preferences interacts with other factors to influence the amount of walking. Certainly, some of 
the influence of the personal preference occurs at the moment of the trip decision. But much of the influence of the values and preferences takes place at the time of residential selection. Indeed, the question of timing of the influence of personal predilection to walking is central to the debate about pre-selection as a source of bias in the use of cross-sectional data to describe the relationship between urban form and level of walking.

The tools of social psychology have been applied to the question of walking in several important studies. In the Adonis Project, Forward adapted the Theory of Planned Behavior to the question of walking by adding both habit and prior behavior to the analysis of the short-distance trip (Forward 2003). The question of habit has been raised, providing an alternative framework from the rational choice emphasis of the TPB (Aarts 1997; Bamberg and Schmidt 2002.) A possible reconciliation between the two approaches has been proposed by Harms, who found that, while habit does indeed explain much of day-to-day behavior, it does not negate the logic that, at some time, rational choices are made on a cognitive basis (Harms 2003). When habit (non-cognitive) is challenged, a rational decision must be made to determine what to do in the face of changes in the context supportive of the habitual behavior (Bamberg, Ajzen, and Schmidt 2003). In short, the literature tends to support the application of a cognitive model based on some level of assumption of rational behavior, with the understanding that more emotion-based or affective motivations may be somewhat understated in such an approach.

\section{Method}

The present study develops a full application of latent factor/ structural equation modeling to more fully explore the question of the timing of the influence of values and preferences and their interactions with other variables. SEM programs, such as AMOS 16 (used here), also allow for the quick documentation of the extent to which total effects of an independent variable on the outcome variables occur in a direct or indirect manner (see Kline 2005). The full application of SEM (i.e., with the inclusion of unobserved latent factors) should, in theory, allow for an effective manner in which to examine the interaction between and among the factors having some kind of effect on the amount of utilitarian walking undertaken. This should be particularly true in the examination of a pattern where an independent variable affects a dependent variable through its influence on a mediating variable. In addition, the explicit inclusion of latent variables that theoretically underlie the observed variables allows the application of Confirmatory Factor Analysis throughout the analysis process. This paper explores the use of a wide range of observed variables, including residential density, employment density (both calculated per square mile), roadway configuration (number of intersections per square mile), and number of vehicles per adult in the household. Also included are self-reported demographics of the individual, as well as a wide range of attitudes and beliefs about choice of residence and choice of mode.

\subsection{Participants and design}

The research is based on a cross-sectional survey, which includes information collected on a retrospective basis in 2004, as part of a larger research process described in detail in TCRP Report 123 (2008). The final sample included 579 persons who had either recently made a residential location decision or were considering making one. The sample was selected to improve the understanding of people's decision to move to a TOD, referred to in the project as a "compact neighborhood." The sample was drawn from 11 major metropolitan areas distributed across the United States, all of which are served by public transportation systems that have been in place for several decades. All 579 were selected from a commercially owned panel of 40,000 Internet respondents (TCRP 2008). Within the sample, 49 percent were under 30 years of age, while 18 percent were between 30 and 40 years of age, reflecting the group of mobile persons making or considering changes in their residential location. Females made up 77 percent of the sample, while 81 percent were white/Caucasian and 64 percent had a college degree. There was an average of 0.87 cars per adult in the sample. The net response rate was estimated at 42 percent, based on the incidence rate for those who have moved within the past two years and accounting for undeliverable e-mail invitations. The survey was specifically designed to oversample groups within regions with good public transportation and was not meant to represent a population-proportional national random sampling. Its purpose was to increase the understanding of the motivations of certain individuals who are of major interest to policymakers trying to promote "smart growth" and environmentally friendly modes.

\subsection{Model specification for the measurement model}

Review of data resources. At the commencement of the modeling process, key variables were reviewed for their suitability for inclusion. Each candidate variable was examined for potential problems with non-normality, and some were modified in form. Income was expressed as the square root of income; both residential density and employment density were converted to a square root format. The survey respondents were reviewed in 


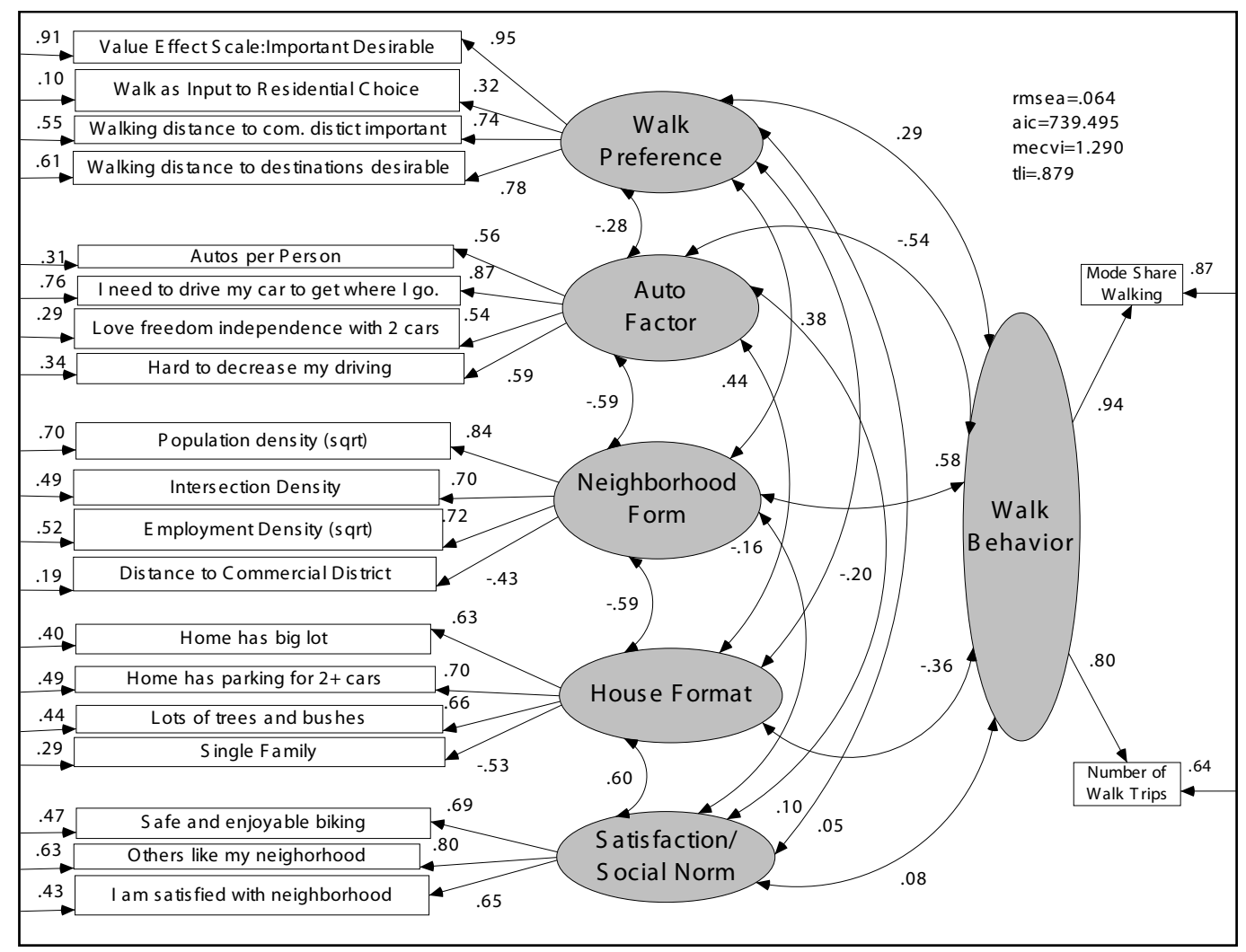

Figure 1: Model 1-Initial measurement model for modifications.

terms of potential outliers. As a precaution, a reduced sample was created that deleted those with the highest level of Mahalanobis $\mathrm{d}$-squared values. However, a sensitivity test of the final models was undertaken, which did not show any clear pattern of model structure change from the smaller sample. It was determined that the possible deletion of legitimate observations posed more of a problem than was merited by the use of the reduced sample, and the full sample was used in the analysis.

The application of the full SEM procedure is largely in a mode of "confirmatory analysis" first undertaken on the "measurement model," which establishes the validity of the latent factors, and then on the "structural model," which establishes the relationship among the latent factors. This is sometimes referred to as the "two-step" approach and is strongly recommended in the SEM literature (Kline 2005; Schumacker and Lomax 2004). The specification of the initial factors to be used in the measurement model was based on work by the authors on the application of the TCRP database over time, using traditional methods including hierarchical regression analysis in SPSS. The five factors applied to the question of walking behavior (Figure 1) are also largely consistent with the published literature; for example, the factors revealed in our hierarchical regression process are similar to those used by Cao et al. (2007) in a SEM path model, which also included variation in driving behavior. The five factors included in the measurement model are:

1. Walk Preference. A factor representing the values and preferences of the individual toward the idea of walking to utilitarian destinations such as shops, restaurants, and a library, as activated through its application at the time of residential selection.

2. Neighborhood Form. A factor representing the urban form of the neighborhood.

3. House Format. A factor representing the urban form of the residence.

4. Auto Factor. A factor representing the individual's level of auto ownership and perceived need for travel by car.

5. Satisfaction/Social Norm. A factor representing the level of satisfaction with the neighborhood and its safety, as perceived both by the individual and by those whose opinions she or he values.

The measurement model seeks to establish that each of the factors reflects the measurements they are supposed to represent. Each of the five factors is assumed to underlie a set of candidate direct observations, which are shown on the lefthand side of the graphic depicting the initial model, presented as Figure 1. The model refinement process was then used to find only those observed measures that result in the best-fitting 
measurement model consistent with the theory being examined.

Model estimation for the measurement model. Examination of the initial measurement model (with a set of the candidate measures included) suggests that we are on the right track, but that model refinement is clearly called for. The Comparative Fit Index (CFI) for the initial measure model is 0.91 , less than the desired 0.95 for a well-fitting model. The Tucker Lewis Index is 0.88 , less than the 0.95 we would seek to see. The root mean square error of approximation (RMSEA) is 0.064; we would like to see 0.05 or under. The opening Akaike Information Criterion (AIC) is at level 739, which is high relative to later models in this paper. The model was properly identified, as the number of degrees of freedom exceeds the number of distinct parameters to be estimated, and each latent variable has been determined by two or more observed variables; thus, it was accepted by the AMOS 16 software program (Arbuckle 2007), converging to an acceptable minimum discrepancy matrix solution. Nineteen out of the 21 measures have factor loadings with a standardized coefficient of 0.5 or above; all 21 of the unstandardized coefficients are statistically significant at $\mathrm{p}$ $<.0001$ (not shown). In short, the initial list of candidate-observed measures does not include any inappropriate variables for further testing and confirmatory refinement.

\subsection{Model modification for the measurement model}

Each unobserved latent factor was refined under the recommended procedures for modification of the measurement model. Each observed measure was reviewed for the magnitude of its factor loading relative to the latent factor, and those with weaker loadings were individually tested for deletion ("model trimming"). For each candidate deletion, the AIC value for the full measurement model was observed; for each set of deletions and combinations of remaining variables, a lower AIC (better) led to the decision to accept the model modification. Each deletion was reviewed in terms of the logic and theory behind the model and for the creation of Heywood cases, which can signal a wide variety of underlying problems with the process, such as multicollinearity. Further, in cases where the AIC improvement was not clearly significant, a second process was applied. A bootstrap model evaluation process (Arbuckle 2007) was undertaken, in which models before and after a candidate deletion are compared for the lower maximum likelihood discrepancy (implied versus population), which has been averaged from the results of 1000 separate pseudo samples. In this manner, the bootstrap model evaluation process allows for a modelfitting procedure that is not affected by the non-normality of the input data and that serves as a cross check for the results of the application of the other indices. In addition, free-standing observed variables were examined for combination in a summary score (summated variable) based on the acceptability of the resultant Chronbach's alpha.

Each final latent factor is summarized below in terms of the candidate measures tested and those included in the proposed model.

The latent factor representing "Walk Preference." Three separate approaches were tested to find the best set of direct measures for walking preference. In the first approach, measures were utilized that only measured the attitudes toward utilitarian walking. Because the measure is designed to explore the attitudes operant at the time of residential selection, and because people have a wider set of interests at that time than just walking to shops and restaurants, a second approach included attitudes toward walking and transit together. A third approach followed this logic and included attitudes toward walking, transit, and house style preference.

The results were instructive. The AIC index for the full measurement model essentially shows that, in the study leading to the outcome variable "walking behavior," the most effective set of preferences/values are about walking and walking only. Models that only included walk preferences at the time of residential selection had a much better model fit than models which included transit, house style, or both. The best model fit included a measure of the extent to which walking was a consideration in the selection of the individual's present home, as reported by the survey participant. The use of retrospective questioning of the extent to which walking was a factor in the actual residential selection was proposed by Handy and colleagues in several studies. An additional direct measure was used, reflecting an expectancy-value scale in which the individual's evaluation of the desirability and importance of living in a walkable neighborhood is multiplied by the expectancy that such an environment would indeed make it easier to get to those places. Use of this scale is consistent with both the Theory of Reasoned Action and the TPB, and is discussed by Fishbein and Ajzen (2010, p. 120-125).

Thus, the unobserved latent factor Walk Preference is constructed from direct observations that both reflect decisions made at the time of residential location and a more general (not time-specific) set of values, presumably operant both then and now.

The latent factor representing "Auto Dependence." The best model fit for the measurement model was produced by creating an Auto Dependence latent factor by use of the observed measure for auto dependency ("I need my car to get where I go" on a seven-point Likert scale) and an observed measure reporting the actual number of automobiles per per- 
son in the household. Other candidates tested but not included in the final model included "I love the feeling of freedom and independence from owning several cars" and "It would be difficult for me to drive less."

The latent factor representing "Urban Neighborhood Form." The best model fit for the measurement model was attained by the use of the observed-measure residential population density (applied as a square root) and an observed measure of the density of intersections per square mile. Other candidates not selected included the distance to the nearest commercial district and the employment density (applied as a square root). Previous consideration had been given to several factors representing a jobs/housing balance and the extent of mix of housing types, which resulted in models with poor fit. Thus, the model incorporates a continuous variable for density and street intersections, which represents a theoretical improvement over simple dichotomous (e.g., urban versus suburban) or other a priori categories used in some studies.

The latent factor representing "Suburban House Format." The best overall model fit for the full measurement model was obtained by using two variables. The first observed variable is a summed scale (alpha $=.62$ ) consisting of "house has a large lot" and "house has garage for two cars." The second observed variable is from "My neighborhood has lots of trees and bushes," which reflects suburban attributes of the house setting, with more trees and bushes associated with lower walk- ing. Together, the latent factor House Format reflects to some extent the "suburban" form of house format and spacing, generally similar to the concept of "outdoor spaciousness" (Cao et al. 2007, based on earlier work by Handy et al.).

The latent factor representing "Satisfaction/Social Norm." The latent factor representing both one's own satisfaction with the present neighborhood and the approval of others with the neighborhood was developed by use of three observed measures: (1) personal satisfaction with my neighborhood, (2) safe and enjoyable biking, and (3) a scale obtained by multiplying "Others think my neighborhood is nice" by the extent to which the participant cares what others think (used as a measure of motivation to comply with the TPB, discussed by Fishbein and Ajzen, p. 127.) A slightly better overall model fit would have been obtained from the use of only two variables, "Others think my neighborhood is nice" and "My neighborhood is a safe and pleasant place for biking." Because we were interested in the extent to which the survey participant was also satisfied with the neighborhood, we allowed the selected solution for this latent factor.

The latent factor representing "Walk Behavior." The latent factor for walking behavior is based on observed measures for walk mode share and for the total amount of utilitarian walk trips. Exploration of a possible third observed measure to reflect only non-work trips did not improve the performance of the model, and its inclusion was rejected.

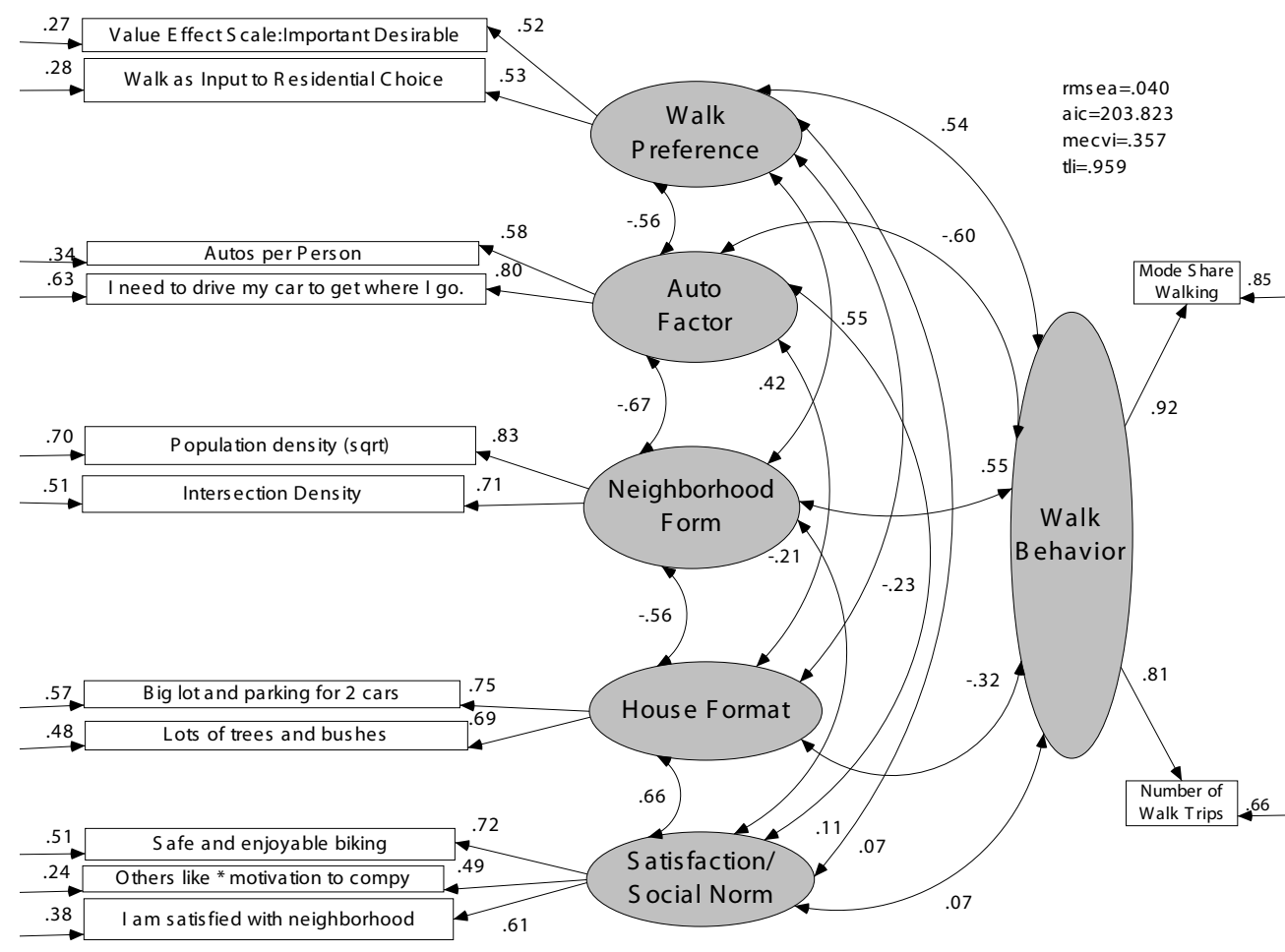

Figure 2: Model \#1-The final measurement model. 
The result of this confirmatory factor analysis process, used as the measurement model for the structural regression phase, is presented here. The final measurement model has a RMSEA of 0.04, a Tucker Lewis Index of 0.96, and a CFI of 0.98. As shown in Figure 2, of the 13 observed measures included in the measurement model, 12 have a standardized factor loading of 0.5 or above: the unstandardized coefficients are statistically significant at $\mathrm{p}<.0001$ (not shown). The final measurement model's convergence and discriminant validity are supported by the fact that indicators of selected constructs load uniquely onto separate latent factors and that none of the correlations between pairs of latent factors were dangerously high, (e.g., 0.85) (Brown 2006). In sum, the selection of the accepted direct measures was undertaken by a strict process of optimized model fit with the exception of satisfaction/social norm, where observed variables were allowed to reflect both the satisfaction of the participant and that of those persons whose opinions he or she respects.

\subsection{Developing the structural model}

The demographics. Of the traditional demographic list, only gender and income were significant. All models were run with and without the demographics. In each case, strict applications of model fit maximization would argue for deleting the vari- ables, but established theory resulted in our decision to leave them in.

Model specification/model refinement process for the structural regression model. A series of models was developed manually to examine the possible interrelationships among the five factors established in the measurement model and their relationship to the outcome of walking behavior. Many different models were tested and refined manually, in a manner designed to explore the theory-based relationships between/ among the six latent variables. As a cross-check of the bestfitting model, the specification search function of AMOS was employed, in which all candidate lines consistent with theory were tested to explore possible relationships between the five explanatory latent factors and their impact on the specified outcome factor, walking behavior. The major contribution of this process was the addition of a "nonrecursive" element of the model, in which urban neighborhood form is seen to influence the house format, and house format is seen to influence the choice of neighborhood, which is quite consistent with theory. The nonrecursive model (Figure 3) produced a "stability index" of 0.102 , which is well below the danger threshold of 1.0 , and thus the model was accepted. (The numbers presented within each oval show the standardized total effect of each latent factor on the outcome latent factor, discussed below).

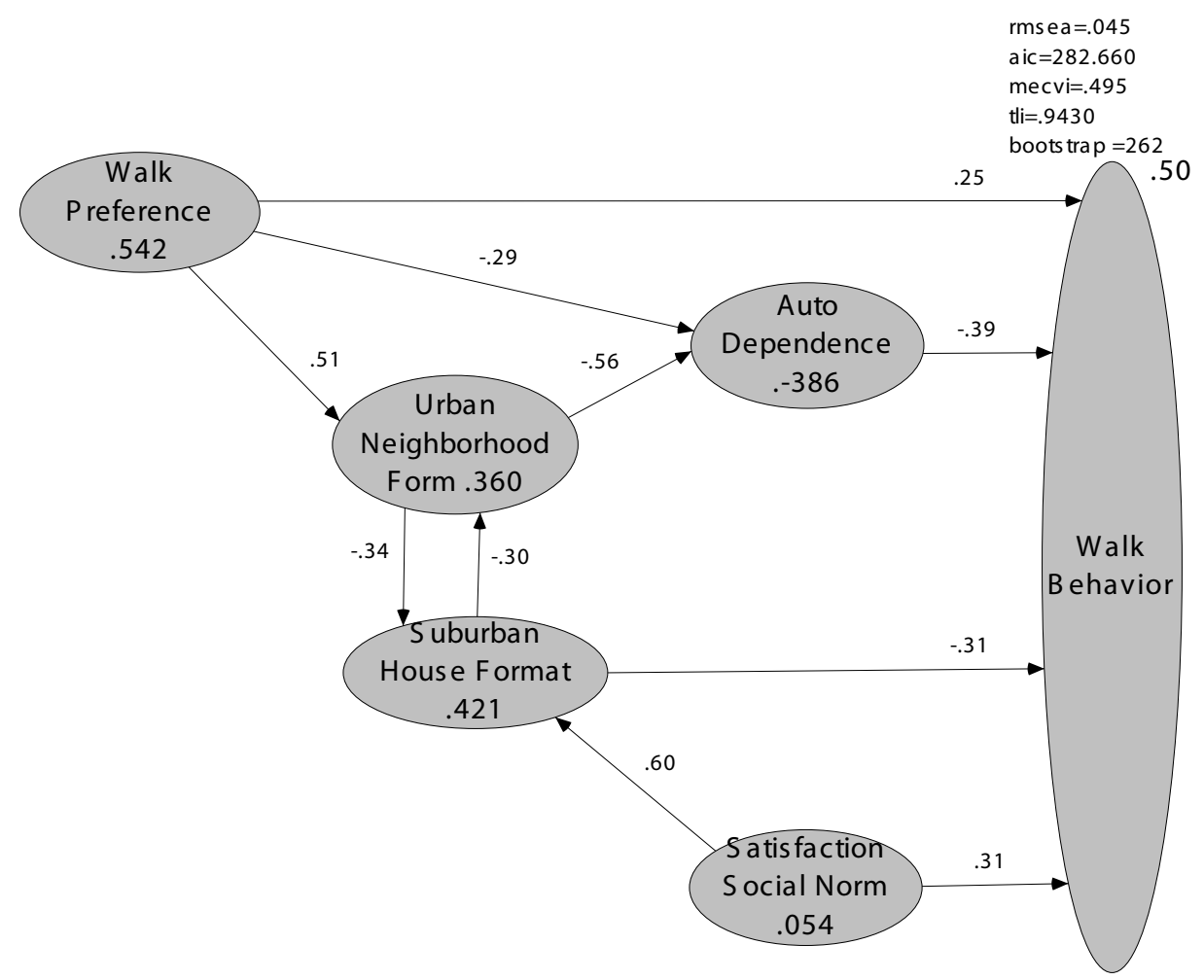

Figure 3: The structural regression model, standardized beta values shown. (All coefficients in the model are significant at $\mathrm{p} \leq .02$ ). Total standardized effects on walk behavior are shown within the oval for each latent factor. 


\section{The results}

Figure 3 shows the structural regression model created based on the selected measurement model, shown without graphic inclusion of its observed indicator variables or the demographic variables. It is examined in terms of overall model fit, its explanatory power, the standardized total effects on its endogenous variables, and its direct effects.

\subsection{Model fit}

Both the model and the separate parameters that comprise the model have a good model fit. For the model as a whole, the results are also positive. The final model has a CFI of 0.96 (above 0.95 preferred); a similar evaluation method, the Tucker-Lewis Index, is above 0.94 (upper 0.90s preferred). With a RMSEA of 0.045 (less than 0.05 preferred), the model has an 81 percent probability that the actual RMSEA is lower than 0.05 (above 70 percent probability preferred). The chi square divided by the degrees of freedom is less than 2.2, well within the desired limits. On the other hand, the probability that the null case is rejected by the chi square statistic alone is not revealed by the "p" value, which should be above 0.05 to meet this criterion; the failure of the chi square measure to reject the null case is common to models with large samples (such as ours), and its relevance as a measure is under debate (Byrne 2001). The AIC measure for the final model is the lowest of all the structural models tested with this measurement model; the results of applying the AIC in model modification was reaffirmed by the application of the bootstrap model comparison technique. In short, the model is robust both in terms of individual parameters and of overall evaluation.

Explanatory power of the model. The model seems to have acceptable explanatory power. The endogenous factor of greatest interest to this research, Walk Behavior, has a squared multiple correlation of 0.50 ; other endogenous factors also have satisfactory $r^{2}$ equivalents, with 0.60 for the Auto Dependence factor; 0.55 for Urban Neighborhood Form; and 0.64 for Suburban House Format.

\subsection{Total effects on the endogenous latent factors}

A key characteristic of SEM is the ability to express relationships between and among factors in terms of the combination of direct and indirect effects, which, when added together, are referred to as "total effects," with standardized total effects used in this paper. The meaning of "total effect" is described in AMOS:

"The standardized total (direct and indirect) effect of Walk Preference on Walk Behavior is 0.542. That is, due to both the direct (unmediated) and indirect (mediated) effects of Walk Preference on Walk Behavior, when Walk Preference goes up by 1 standard deviation, Walk Behavior goes up by 0.542 standard deviations."

The overall effect of each predicting factor on each endogenous factor is shown in Table 1. For example, the "total effect" on Urban Neighborhood Form from Walk Preference is 0.567. (An increase in Walk Preference of one standard deviation would predict a change in Urban Neighborhood Form by 0.567 standard deviations.) The bottom row of Table 1 shows the level of total effect (in bold) from each of the five latent factors and from the two demographic variables on the propensity to undertake utilitarian walking. In our sample, being male is associated with increased levels of utilitarian walking; having a higher income is associated with higher levels of the Auto Dependency factor. Being male is associated with a higher propensity to live in an urban neighborhood, with a lower propensity to live in a suburban-formatted house and be auto dependent.

Table 2 shows the unstandardized values for the direct effects and presents the statistical significance of each, all of which are significant at $\mathrm{p} \leq .02$, except for Income to Walk Factor at $\mathrm{p} \leq .05$. The right-hand column of Table 2 shows the standardized coefficients for all the parameters between the factors (the standardized direct effects.)

The basic structural model reproduced here as Figure 3 reveals an interesting set of interrelationships among the five interacting latent factors and the outcome factor, Walk Behavior.

- The model suggests that the values and preferences for walking most importantly (beta $=.51$ ) influence the suburban versus urban location decision about the type of neighborhood; these same values/preferences also influence walking directly (beta $=0.25)$ and im-

Table 1: Standardized total effects on endogenous factors.

\begin{tabular}{|c|c|c|c|c|c|c|c|}
\hline & $\begin{array}{c}\text { Walk } \\
\text { Preference }\end{array}$ & $\begin{array}{c}\text { Urban } \\
\text { Neighborhood } \\
\text { Form }\end{array}$ & $\begin{array}{c}\text { Suburban } \\
\text { House Format }\end{array}$ & $\begin{array}{c}\text { Auto } \\
\text { Dependence }\end{array}$ & $\begin{array}{l}\text { Satisfaction } \\
\text { Social Norm }\end{array}$ & Income & Male \\
\hline Urban Neighborhood Form & 0.567 & 0.113 & -0.330 & 0.000 & -0.199 & 0.000 & 0.194 \\
\hline Suburban House Format & -0.194 & -0.382 & 0.113 & 0.000 & 0.672 & 0.000 & -0.066 \\
\hline Auto Dependence & -0.609 & -0.620 & 0.184 & 0.000 & 0.111 & 0.211 & -0.108 \\
\hline Walk Behavior & 0.542 & 0.360 & -0.421 & -0.386 & 0.054 & 0.010 & 0.152 \\
\hline
\end{tabular}


pact the level of self-reported auto dependence (beta $=0.29$ ).

- The characteristics of Urban Neighborhood Form (density and street layout) serve as a powerful explainer of perceived auto dependence and the number of autos owned (beta $=-0.56$ ).

- The latent factor Urban Neighborhood Form serves to explain Suburban House Format (beta $=-0.34$ ), while House Format serves to explain Neighborhood Form (beta $=-.30)$. This relationship makes the model "nonrecursive" in nature and acknowledges the mutual directionality revealed.

- The latent factor House Format serves to negatively explain Walk Behavior (beta $=-0.31$ ).

- Urban Neighborhood Form does help to explain Walk Behavior-but indirectly through the mediating factors of House Format and Auto Factor. (Although we hypothesized that the direct coefficient between Neighborhood Form and Walk Behavior would be significant, it was not, and so was deleted from the model.)

- The latent factor Satisfaction/Social Norm positively explains Walk Behavior (beta $=0.31$ ). In addition, satisfaction with the neighborhood is highly correlated with having a suburban format for the residence, which is negatively correlated with Walk Behavior.

Of these observations, the role of auto dependence is perhaps the most interesting. In this model, the level of auto dependency is influenced by the suburbanness of the overall neighborhood and by the set of attitudes/preferences involved in the selection of the neighborhood. Thus, the latent factor

Table 2: Regression weights.

\begin{tabular}{|c|c|c|c|c|c|c|c|}
\hline & & & Estimate & S.E. & C.R. & $\mathrm{P}$ & $\begin{array}{c}\text { Standardized } \\
\text { beta }\end{array}$ \\
\hline Suburban House Format & $<--$ & Urban Neighborhood Form & -0.007 & 0.001 & -5.21 & $* * *$ & -0.343 \\
\hline Suburban House Format & $<--$ & Satisfaction Social Norm & 0.557 & 0.062 & 8.947 & $* * *$ & 0.603 \\
\hline Urban Neighborhood Form & $<--$ & Suburban House Format & -14.358 & 3.236 & -4.437 & $* * *$ & -0.297 \\
\hline Urban Neighborhood Form & $<--$ & Walk Preference & 36.55 & 6.596 & 5.541 & $* * *$ & 0.509 \\
\hline Urban Neighborhood Form & $<--$ & Male & 23.25 & 5.309 & 4.379 & $* * *$ & 0.174 \\
\hline Auto Dependence & $<--$ & Walk Preference & -0.539 & 0.181 & -2.982 & 0.003 & -0.293 \\
\hline Auto Dependence & $<--$ & Urban Neighborhood Form & -0.014 & 0.002 & -6.829 & $* * *$ & -0.557 \\
\hline Auto Dependence & $<--$ & Income & 0.169 & 0.038 & 4.481 & $* * *$ & 0.211 \\
\hline Walk Behavior & $<--$ & Walk Preference & 0.049 & 0.02 & 2.514 & 0.012 & 0.245 \\
\hline Walk Behavior & $<--$ & Auto Dependence & -0.042 & 0.011 & -3.995 & $* * *$ & -0.386 \\
\hline Walk Behavior & $<--$ & Suburban House Format & -0.043 & 0.013 & -3.235 & 0.001 & -0.314 \\
\hline Walk Behavior & $<--$ & Satisfaction Social Norm & 0.039 & 0.011 & 3.478 & $* * *$ & 0.308 \\
\hline Walk Behavior & $<--$ & Income & 0.008 & 0.004 & 2.037 & 0.042 & 0.092 \\
\hline Walk Behavior & $<--$ & Male & 0.034 & 0.014 & 2.392 & 0.017 & 0.090 \\
\hline
\end{tabular}

Auto Dependence serves as a mediating factor between both Walk Preference and Urban Neighborhood Form and the outcome variable, Walk Factor. In fact, Auto Dependence emerges as having the highest level of direct effect on Walk Factor (beta $=0.39$ ), with walking decreasing as auto dependence increases.

All elements of the final model are presented as one graphic in Figure 4, which includes the structural regression elements, the observed indicators from the measurement model, and the two demographic variables.

Seen from a temporal perspective, the model can be interpreted as having three distinct time phases: a residential selection phase at the beginning, a satisfaction/evaluation phase at the end, and an equilibrium phase in the middle. In the equilibrium phase, a robust interaction between values, neighborhood form, housing format, and auto dependence takes place; once the setting has been established, it can be evaluated in terms of satisfaction. This is consistent with the overall framework established by Ben-Akiva (1983) and others, and with the evolving theory by Van Acker, Van Wee, and Witlox (2010) in a relevant article that seeks to better integrate transport behavior with theories of social psychology, including the Theory of Planned Behavior.

\subsection{Decomposition to model "Built Environment"}

The model clearly differentiates between the latent factor associated with the density/form of the neighborhood and the spaciousness of the individual residence. If, however, the model is to be applied in terms of the broader category of "Built Environment," the standardized total effect of "Urban Neighborhood Form" merged with "Suburban House Format" can be 


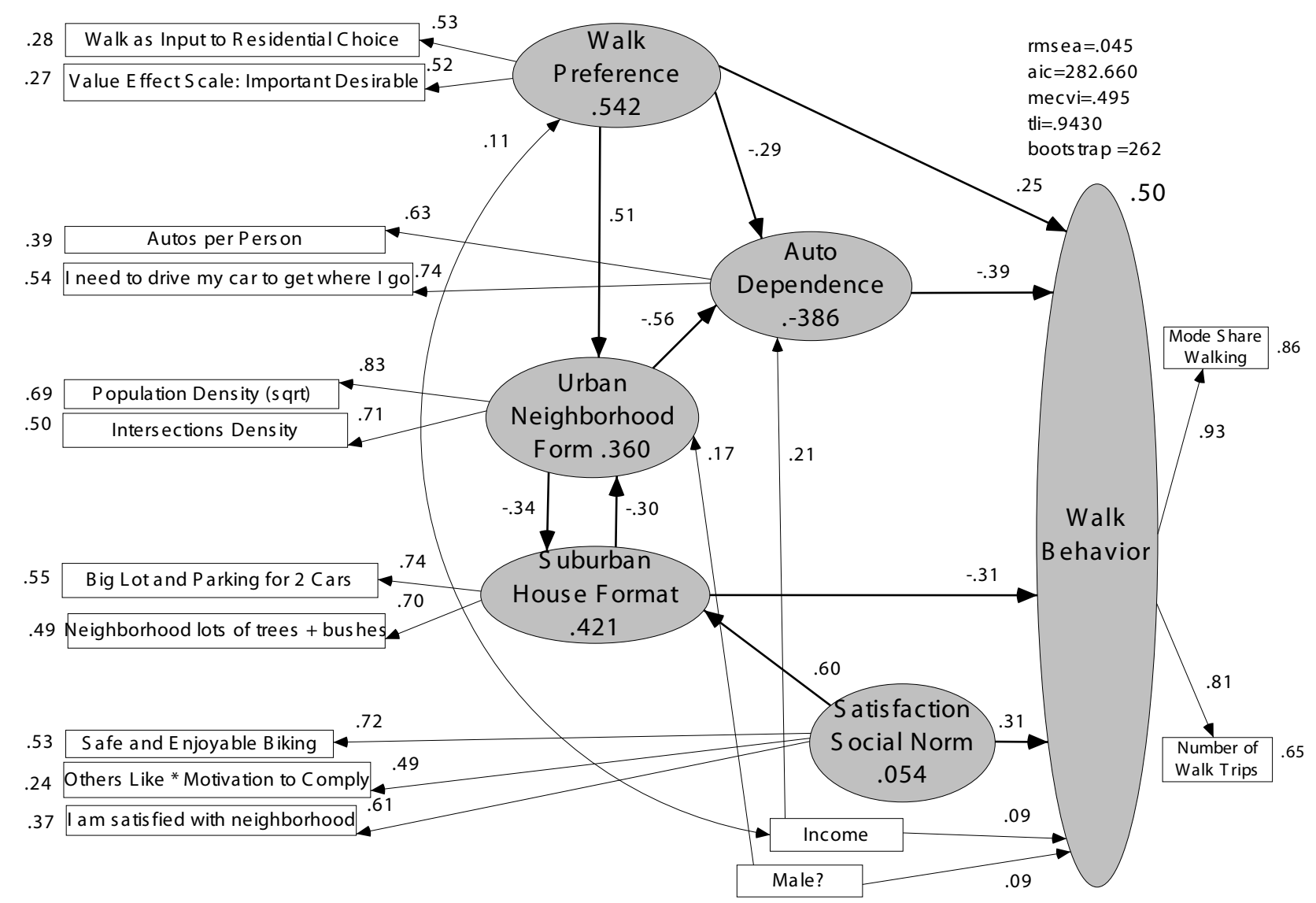

Figure 4: Diagram including measurement model, structural model, and demographics.

calculated by a traditional tracing exercise, which accounts for all variation in walk behavior attributable to the two existing factors while controlling for any double counting. In total, the model has 12 traced paths, whether direct or via a mediating factor, between our five predictor factors and our outcome factor, Walking Behavior. (An example of an indirect traced path is Walk Preference-->Urban Neighborhood Form-->Auto Dependence--> Walk Behavior.] The case for manually examining the total effects for each path is made by Kline (2005).

The tracing exercise reveals that the influence of Built Environment upon Walking Behavior is very similar in scale to the influence of Walk Preference upon Walking Behavior. The Built Environment has a standardized total effect value of 0.53, made up of 0.31 from the direct path and 0.22 from the indirect path. Walk Preference has a standardized total effect value of 0.52 , made up of 0.25 from direct and 0.27 from indirect paths. The two indirect paths reflect the pattern of interaction between the two factors; the two direct paths reflect the "stand alone" influence of each. Thus, our findings are consistent with the current consensus that values/preferences often interact with the built environment in influencing transportation behavior, above and beyond their own unique impacts.

\section{Discussion}

The application of the full structural regression model process, based on the use of unobserved latent factors, has rarely been applied to the question of walking. The strengths of the method, including the ability to apply confirmatory factor analysis throughout the analysis process and the ability to examine multiple roles for endogenous factors, make it a good candidate for further work in the examination of a process characterized by the interplay between direct and indirect impacts, i.e., those involved with mediating factors.

This is particularly important in the examination of a process with a complex temporal setting. In the examination of walking behavior, part of the impact of our values and preferences occurs at the time of residential selection and part occurs at times closer to the actual decision to walk. In addition, these values seem to surface as we settle in on the number of cars owned and the concurrent feeling of auto dependence. 
The models also shed light on the role and timing of auto orientation in determining walking behavior. The structural regression suggests that the urban form of the neighborhood impacts the Auto Dependence factor, which in turn impacts the Walk Behavior factor. The model suggests that the size of your lawn does not influence your level of auto dependence, but the density of the neighborhood does. The model shows this to be a strong relationship: a change of one standard deviation in the Urban Neighborhood Form factor would predict a change of more than 0.5 standard deviations of the Auto Dependence factor.

\section{Comparison of importance of preferences versus the built environment}

From the outset, our model was structured to reflect the interactions in the paths from values to behavior, utilizing concepts commonly applied in social psychology. We do not posit that land density and form causes walking behavior, any more than we would posit that an exercise machine in the basement causes one to exercise. The outcome behavior, exercise, results when some level of volition is either enabled or impeded by the mediating factors of the immediate environment. For some, having an exercise machine in the basement will make it easier to exercise, resulting in a belief that one has more "control" over the behavior and can actually accomplish it. The immediate environment containing the exercise machine is seen as a (enabling) mediating factor between the volition and the behavior.

In the determination of utilitarian walking, the built environment also serves as a mediating factor between the volition and the behavior. Our latent factor Walk Preference reflects the level of inclination toward utilitarian walking, including a general feeling that it is important and/or desirable, and the extent to which these feelings were accessed in the residential decision. To some extent the built environment serves as a mediating factor in enabling or impeding that inclination. Considering its role in both direct and indirect impacts of the built environment, just how big is that factor?

Our decomposition analysis shows that paths that start with Walk Preference produce a "total effect" on Walk Behavior of 0.52; paths that start with the Built Environment produce a "total effect" on Walk Behavior of 0.53 . The model confirms that the set of values and preferences reflected in the Walk Preference factor play an important role in explaining the Walk Behavior latent factor-but, they do not dominate it by any definition. In short, there is no evidence from this study that the set of values and preferences that were operant at the time of residential choice diminishes or negates the importance of the built environment as a determinant factor, among others. To the contrary, when all the components affecting Walk Behavior are accounted for in the model, the components of the built environment provide just as much explanatory power ("total effect") to the question of utilitarian walking as does Walk Preference. From the present model there is no evidence that walking behavior is primarily attributable to values/preferences operant at the time of residential choice, dominating over the impact of the built environment.

In a comprehensive review of the effect of "pre-selection" attitudes on transportation behavior, Cao et al. (2008) recommended that the analysis of the importance of the pre-selection variable in SEM models be determined by isolating the incremental contribution to the r-square equivalent (for walk behavior) attributable to built environment, and comparing that with the incremental contribution to the r-square equivalent attributable to built environment and attitude taken together. Based on the application of this formula to our data, the "proportion of the total effect of $\mathrm{BE}$ [built environment] on $\mathrm{TB}$ [transportation behavior] due to $\mathrm{BE}$ alone rather than due to the effect of AT [attitude] on BE" is 50 percent (Cao et al. 2008 , p. C-9). The result from this method is totally consistent with our conclusion above that the SEM total effect of the built environment on walking is roughly equal to the SEM total effect of the attitudes/preferences at the time of residential selection.

\section{Conclusion}

The project, "Understanding How Individuals Make Travel and Location Decisions: Implications for Public Transportation," was designed to create an integrated approach to the analysis of location and mode decisions. The values and preferences represented by the Walk Preference factor are seen as a totally integral part of the process that influences the level of utilitarian walking. A seminal document from the Transportation Research Board (TRB-IOM 2005) asks:

"Do people walk more in a particular neighborhood because of pleasant tree-lined sidewalks, or do they live in a neighborhood with pleasant tree-lined sidewalks because they like to walk..."

The full application of structural regression modeling based on latent factors, applied to a database that properly incorporates the residential decision, suggests that the answer is "both." Having a predilection toward walking directly influences the kind of neighborhood you pick and indirectly, the form of the house you choose within that neighborhood. But properly including this attitudinal factor in the model by no 
means negates the considerable importance of having a built environment that supports and enables the effectuation of the predilection towards walking. Rather, our model suggests that the two factors are just about equal in importance and are highly interactive. The built environment does influence walking, as does the level of auto dependence and the level of satisfaction with the neighborhood. Each of these serves to either enable or impede the effectuation of the initial inclination to walk. Our research on Americans from transit-rich metropolitan areas generally supports the existing literature (Van Wee 2009), in which the concept of self-selection as a source of systematic bias is being replaced by a vision in which the values and preferences held at the time of residential choice are seen as an integral element for understanding transportation behavior.

\section{Acknowledgements}

The research has been funded within the Transit Cooperative Research Program of the Transportation Research Board, with funding from the Federal Transit Administration of the United States Department of Transportation (USDOT). Further analysis has been funded by the New England Transportation Institute, White River Junction, Vermont, with support through a grant from the Federal Highway Administration of the USDOT.

\section{References}

Aarts, H., B. Verplanken, and A. van Knippenberg. 1997. Habit and information use in travel model choices. Acta Psychologica, 96(1-2):1-14. doi: 10.1016/S0001-6918(97)00008-5. URL: http://www.sciencedirect.com/science/article/pii/ S0001691897000085.

Acker, V. V., B. van Wee, and F. Witlox. 2010. When transport geography meets social psychology: Toward a conceptual model of travel behaviour. Transport Reviews, 302):219240. doi: 10.1080/01441640902943453.

Acker, V. V. and F. Witlox. 2010. Car ownership as a mediating variable in car travel behaviour research using a structural equation modelling approach to identify its dual relationship. Journal of Transport Geography, 18(1):65-74. doi:10.1016/j.jtrangeo.2009.05.006.

Ajzen, I. 1991. The theory of planned behavior. Organizational Behavior and Human Decision Processes, 502):179-211. doi: 10.1016/0749-5978(91)90020-T. URL: http://www. sciencedirect.com/science/article/pii/074959789190020T.

Ajzen, I. 2008. Theory of planned behavior. URL: http://www. unix.oit.umass.edu/ -Ajzen/tpb.html.

Anable, J. 2005. "Complacent car addicts" or "Aspiring environmentalists?": Identifying travel behaviour segments using attitude theory. Transport Policy, 12(1):65-78. doi: 10.1016/j.tranpol.2004.11.004. URL: http://www.sciencedirect.com/science/article/pii/S0967070X0400054X.

Arbuckle, J. L. 2007. Amos 16.0 User's Guide. Chicago, SPSS, Inc.

Bagley, M. N. and P. L. Mokhtarian. 2002. The impact of residential neighborhood type on travel behavior: A structural equations modeling approach. Annals of Regional Science, (362):279-297. doi: 10.1007/s001680200083.

Bamberg, S., I. Ajzen, and P. Schmidt. 2003. Choice of travel mode in the theory of planned behavior: The roles of past behavior, habit, and reasoned action. Basic and Applied Social Psychology, 25(3):175-187. doi:10.1207/ S15324834BASP25030 1.

Bohte, W. 2010. Residential self-selection and travel: The relationship between travel-related attitudes, built environment characteristics and travel behaviour. Number 35 in Sustainable urban areas. IOS Press.

Byrne, B. M. 2001. Structural equation modeling with AMOS: Basic concepts, applications, and programming. London: Lawrence Erlbaum Associates.

Cao, X., P. L. Mokhtarian, and S. L. Handy. 2007. Do changes in neighborhood characteristics lead to changes in travel behavior? A structural equations modeling approach. In TRB 86th Annual Meeting Compendium of Papers CD-ROM, 07-0735. Transportation Research Board. URL http://trid. trb.org/view/2007/C/801278.

Cao, X., P. L. Mokhtarian, and S. L. Handy. 2008. Examining the impacts of residential self-selection on travel behavior: Methodologies and empirical findings. Technical Report CTS 08-24, University of Minnesota, Center for Transportation Studies. URLhttp://www.cts.umn.edu/Publications/ResearchReports/reportdetail.html?id $=1684$.

Cao, X., P. L. Mokhtarian, and S. L. Handy. 2009. Examining the impacts of residential self-selection on travel behavior: A focus on empirical findings. Transport Reviews, 29(3):359-395. doi: 10.1080/01441640802539195.

Cervero, R. and K. Kockelman. 1997. Travel demand and the3ds: Density, diversity, and design. Transportation Research Part D: Transport and Environment, 2(3):199-219. doi:10.1016/S1361-9209(97)00009-6.

Coogan, M. A. 2003. Why care about walking? U.S. Department of Transportation. http://nhts.ornl.gov/2001/presentations/walking/walking.ppt. Accessed December, 2010.

Coogan, M. A., K. H. Karash, T. Adler, and J. Sallis. 2007. The role of personal values, urban form, and auto availability in the analysis of walking for transportation. American Journal of Health Promotion, 21(4s):363-370. doi: 10.4278/08901171-21.4s.363. 
Coogan, P. F., L. F. White, T. J. Adler, K. M. Hathaway, J. R. Palmer, and L. Rosenberg. 2009. Prospective study of urban form and physical activity in the black women's health study. American Journal of Epidemiology, 170(9):11051117. doi: 10.1093/aje/kwp264.

Fishbein, M. and I. Ajzen. 2010. Predicting and changing behavior: The reasoned action approach. Psychology Press.

Forward, S. 2003. Short journeys: Why do we choose the way we do? VTI report, Swedish National Road Transport Research Institute.

Frank, L. D., B. E. Saelens, K. E. Powell, and J. E. Chapman. 2007. Stepping towards causation: Do built environments or neighborhood and travel preferences explain physical activity, driving, and obesity? Social Science Medicine, 65(9):1898-1914. doi: 10.1016/j.socscimed.2007.05.053.

Giles-Corti, B. and R. J. Donovan. 2002. The relative influence of individual, social and physical environment determinants of physical activity. Social Science Medicine, 54(12):1793-1812. doi: 10.1016/S0277-9536(01)001502.

Giuliano, G. 1995. The weakening transportation-land use connection. Access, 6(1):3-11.

Handy, S. L. 2005. Smart growth and the transportationland use connection: What does the research tell us? International Regional Science Review, 282):146-167. doi:10.1177/0160017604273626.

Handy, S. L., X. Cao, and P. L. Mokhtarian. 2005. Correlation or causality between the built environment and travel behavior?: Evidence from northern California. Transportation Research Part D: Transport Environment, 10(6):427-444. doi: $10.1016 /$ j.trd.2005.05.002.

Handy, S. L., X. Cao, and P. L. Mokhtarian. 2008. The causal influence of neighborhood design on physical activity within the neighborhood: Evidence from northern California. American Journal of Health Promotion, 22(5):350-358. doi: 10.4278/ajhp.22.5.350.

Harms, S. 2003. From routine choice to rational decision making between mobility alternatives. In 3rd Swiss Transport Research Conference, March 19-21, 2003. Centre for Innovation Research in the Utility Sector. URL http://www.strc. $\mathrm{ch} /$ conferences/2003.

Karash, K. H., M. A. Coogan, T. J. Adler, C. Cluett, S. A. Shaheen, I. Ajzen, and M. Simon. 2008. Understanding how individuals make travel and location decisions: Implications for public transportation. TCRP report 123, Transit Cooperative Research Program. URL http://trid.trb.org/ view/2008/M/850871.

Khattak, A. J. and D. Rodriguez. 2005. Travel behavior in neotraditional neighborhood developments: A case study in USA. Transportation Research Part A: Policy and Practice, 39(6):481-500. doi: 10.1016/j.tra.2005.02.009.

Kitamura, R., P. L. Mokhtarian, and L. Laidet. 1997. A micro-analysis of land use and travel in five neighborhoods in the San Francisco Bay area. Transportation, 242):125-158. doi:10.1023/A:1017959825565.

Kline, R. B. 2005. Principles and practice of structural equation modeling. Methodology in the social sciences. Guilford Press.

Lerman, S. R. 1976. Location, housing, automobile ownership, and the mode to work: A joint choice model. Transportation Research Record, 610:6-11.

Næss, P. 2005. Residential location affects travel behaviorbut how and why? The case of Copenhagen metropolitan area. Progress in Planning, 632):167-257. doi:10.1016/j. progress.2004.07.004.

Nrss, P. 2006. Accessibility, activity participation and location of activities: Exploring the links between residential location and travel behavior. Urban Studies, 43(3):627-652. doi: 10.1080/00420980500534677.

Næss, P. 2009. Residential self-selection and appropriate control variables in land use : Travel studies. Transport Reviews, 29(3):293-324. doi: 10.1080/01441640802710812.

Newman, P. and J. Kenworthy. 1989. Cities and automobile dependence: An international sourcebook.

Outwater, M. L., S. Castleberry, Y. Shiftan, M. Ben-Akiva,Y. Zhou, and A. Kuppam. 2003. Use of structural equation modeling for an attitudinal market segmentation approach to mode choice and ridership forecasting. In 10th International Conference on Travel Behaviour Research. Cambridge Systematics, Inc. URL: http://www.ivt.ethz.ch/news/archive/20030810_IATBR.

Pinjari, A., R. Pendyala, C. Bhat, and P. Waddell. 2007. Modeling residential sorting effects to understand the impact of the built environment on commute mode choice. In TRB 86th Annual Meeting Compendium of Papers CD-ROM, 07-3149. URL http://trid.trb.org/view/2007/C/802587.

Prevedouros, P. D. 1992. Associations of personality characteristics with transport behavior and residence location decisions. Transportation Research Part A: Policy and Practice, 26(5):381-391. doi: 10.1016/0965-8564(92)90002-O.

Saelens, B. E. and S. L. Handy. 2008. Built environment correlates of walking: A review. Medicine \& Science in Sports of Exercise, 40(7):S550-S566. doi:10.1249/ MSS.0b013e31817c67a4.

Sallis, J. F. and N. Owen. 1999. Physical activity and behavioral medicine. Behavioral medicine and health psychology series. Sage.

Salomon, I. and M. Ben-Akiva. 1983. The use of the lifestyle concept in travel demand models. Environment and Plan- 
ning A, 15(5):623-638. doi: 10.1068/a150623.

Schumacker, R. E. and R. G. Lomax. 2004. A beginner's guide to structural equation modeling. Routledge, 2 nd edition.

Stradling, S. G. 2003. Changing individual travel behaviour: From policy to perceived behavioral control. Technical report, Transport Research Institute, Napier University, Edinburgh.

Stradling, S. G. 2004. Changing individual travel behaviour: From policy to perceived behavioural control. In 3rd International Conference on Traffic and Transport Psychology.

Stroebe, W., E. K. Papies, and H. Aarts. 2008. From homeostatic to hedonic theories of eating : Self-regulatory failure in food-rich environments. Applied Psychology, 57(s1):172193. doi: 10.1111/j.1464-0597.2008.00360.x.

Transportation Research Board-Institute of Medicine. 2005. Does the built environment influence physical activity?: Examining the evidence. Special report, Washington, DC.: National Academies Press.

van Wee, B. 2009. Self-selection: A key to a better understanding of location choices, travel behavior, and transport externalities? Transport Reviews, 29(3):279-292. doi:10.1080/01441640902752961.

Walker, J. L. and J. Li. 2007. Latent lifestyle preferences and household location decisions. Journal of Geographical Systems, 9(1):77-101. doi: 10.1007/s10109-006-0030-0.

Warner, H. M. W. and L. Aberg. 2005. Why do drivers speed? In Underwood, G., ed. Traffic transport psychology: Theory and application. Oxford: Elsevier Ltd. 